\title{
A ATUAÇÃO DA DEFENSORIA PÚBLICA NO ACESSO AO SISTEMA INTERAMERICANO DE DIREITOS HUMANOS: UMA PERSPECTIVA GARANTISTA MULTINÍVEL DE DIREITOS CONSTITUCIONAIS E CONVENCIONAIS
}

\author{
THE PERFORMANCE OF THE PUBLIC DEFENDER IN ACCESS TO THE INTER-AMERICAN SYSTEM \\ OF HUMAN RIGHTS: A MULTILEVEL GUARANTEEIST PERSPECTIVE OF CONSTITUTIONAL AND \\ CONVENTIONAL RIGHTS
}

Ana Maria D'Ávila Lopes ${ }^{1}$

Leandro Sousa Bessa ${ }^{2}$

\begin{abstract}
Resumo: A perspectiva garantista, caracterizada pela proteção e implementação dos direitos fundamentais, vem se impondo como paradigma de atuação do Estado Democrático de Direito. Nos últimos anos, entretanto, essa perspectiva não mais tem se limitado aos sistemas jurídicos nacionais, mas vem também permeando os sistemas internacionais de proteção dos direitos humanos e o diálogo mantido entre estes e aqueles. Nesse contexto, com o presente artigo pretendeu-se investigar a atuação da Defensoria Pública, nesse processo dialógico de proteção interna e internacional dos direitos humanos, sob uma perspectiva garantista multinível de direitos constitucionais e convencionais. Para tal, valeu-se do método dedutivo para a análise dos dados levantados por meio de uma pesquisa bibliográfica, legislativa e jurisprudencial, partindo-se de análises gerais sobre o garantismo e dos sistemas nacionais e interamericanos de proteção dos direitos humanos, para, então, chegar-se à específica construção de um paradigma de atuação da Defensoria Pública brasileira perante o Sistema Interamericano de Direitos Humanos.
\end{abstract}

Palavras-chave: Garantismo. Defensoria pública. Sistema Interamericano. Direitos humanos.

\begin{abstract}
The guaranteeist perspective, characterized by the protection and implementation of fundamental rights, has been imposing itself as paradigm of action of the Rule of Law. In recent years, however, such perspective has no longer been limited to national legal systems, but has also permeated the international systems of human rights protection and the dialogue between the two systems. In this context, this article aims to investigate the Public Defense acting in this dialogical process of internal and international protection of human rights from a multilevel guarantee perspective of constitutional and conventional rights. To this end, it was used the deductive method for the analysis of data collected through a literature, legislative and jurisprudential research, based on general analyzes on the guarantee and on the national and Inter-American human rights protection systems, to, thus, achieve the specific construction of a paradigm the action of the Brazilian Public Defender before the Inter-American Human Rights System.
\end{abstract}

Keywords: Guaranteeism. Public defense. Inter-American system. Human rights.

\footnotetext{
1 Doutora e Mestre em Direito Constitucional pela Universidade de Minas Gerais; Professora Titular no Programa de Pós-Graduação em Direito da Universidade de Fortaleza; Avenida Washington Soares, 1321, Edson Queiroz, 60811-905, Fortaleza, Ceará, Brasil; anadavilalopes@yahoo.com.br

2 Mestre e doutorando em Direito Constitucional pela Universidade de Fortaleza; Professor do Centro Universitário Christus; leandro.bessa@defensoria.ce.def.br
} 


\section{Introdução}

A efetividade de direitos humanos é um dos maiores desafios da contemporaneidade. Após sucessivas conquistas históricas que possibilitaram um acúmulo considerável de promessas legislativas tendentes à consolidação de uma versão cada vez mais ampliada de dignidade humana, resta a construção de instrumentos para a concretização prática dos dispositivos que lograram se estabelecer nos textos constitucionais. Fortalece-se, pois, a perspectiva garantista, comprometida com um Estado Democrático de Direito, cuja atuação, legitimação e finalidades estão guiadas pelo respeito aos direitos humanos e fundamentais.

Por outro lado, a universalidade dos direitos humanos, associada à preocupação dos Estados de abrirem mão de parte de sua soberania em nome de um consenso ético, faz imprescindível o conhecimento e utilização do diálogo entre as fontes nacionais e internacionais de previsão e proteção desses direitos. Em outras palavras, urge a construção de uma perspectiva garantista que abranja tanto as previsões constitucionais quanto as convencionais, possibilitando a interpenetração e a mútua influência entre elas.

As instituições democráticas, no cumprimento de suas finalidades, portanto, devem guiar-se por esse novo paradigma. No caso do presente artigo, busca-se delinear a atuação da Defensoria Pública no acesso ao Sistema Interamericano de Direitos Humanos, como instrumento de fortalecimento de uma perspectiva garantista multinível de direitos constitucionais e convencionais.

Para tal, valeu-se do método dedutivo para a construção do artigo, visto que se partiu de análises gerais sobre garantismo e sistemas nacionais e internacionais de proteção dos direitos humanos, para, então, chegar-se à específica construção de um paradigma de atuação da Defensoria Pública brasileira perante o Sistema Interamericano de Direitos Humanos. A coleta de dados foi realizada por meio de uma pesquisa bibliográfica, legislativa e jurisprudencial.

Desse modo, na primeira seção apresenta-se o paradigma do garantismo, a fim de que se possa inicialmente compreender o objetivo da atuação institucional investigada. Posteriormente, na segunda seção, os aspectos básicos conceituais do Sistema Interamericano de Direitos Humanos são expostos. Na terceira seção, o papel da Defensoria Pública como instituição defensora e promotora dos direitos humanos é salientado. Finalmente, na última seção, as possibilidades de atuação da Defensoria Pública perante o Sistema Interamericano de Direitos Humanos são analisadas, buscando demonstrar seu papel como instituição catalisadora de uma postura dialógica entre as instâncias nacionais e internacionais de proteção dos direitos humanos.

\section{A perspectiva garantista como paradigma}

O primeiro obstáculo que é necessário transpor na presente investigação é estabelecer o paradigma que se entende que deve ser adotado pela Defensoria Pública. A escolha foi pelo garan- 
tismo, definido como o modelo no qual se assenta o Estado de Direito, caracterizado pela proteção e implementação dos direitos fundamentais (STEINER, 2000, p. 93).

Esclarece-se que o modelo garantista aqui adotado é o de Ferrajoli (2006), que defende a superação do Estado autoritário e do positivismo clássico, por meio da alteração da: Teoria do Direito, mediante a revisão da teoria da validade, de forma a aproximar a forma e a substancia das decisões; Teoria política, abandonando a concepção puramente procedimental da democracia; Teoria da aplicação da lei, redefinindo o papel do juiz e as formas e as condições de sua sujeição à lei; e Metateoria do Direito, assegurando que a função da Ciência Jurídica não seja somente descritiva, mas também crítica em relação ao seu objeto.

Para efetivar esse modelo garantista, ganha relevo o advento do constitucionalismo e a consequente limitação dos poderes estatais, seguido do fenômeno da constitucionalização do Direito, a partir do qual foi possível reconhecer a força normativa das constituições. Rosa (2003, p. 34), nesse particular, doutrina que a teoria garantista representa, ao mesmo tempo, o resgate e a valorização da constituição como documento constituinte da sociedade. Nesse diapasão, seguem Streck e Saldanha (2103, p. 413-414), para quem o garantismo é uma maneira de fazer democracia dentro do Direito e a partir do Direito, além da importância de defender, entre outras coisas, que a Constituição (em sua totalidade) deve ser o paradigma hermenêutico de definição do que seja uma norma válida ou inválida, propiciando toda uma filtragem das normas infraconstitucionais que, embora vigentes, perdem sua validade em face da Lei Maior.

Por essa razão, no que tange ao papel da jurisdição em um modelo garantista, Carvalho (2008, p. 102) aduz a defesa intransigente dos direitos fundamentais, topos hermenêutico de avaliação da validade substancial das leis. $O$ vínculo do julgador à legalidade não deve ser outro que a legalidade constitucionalmente válida, sendo imperante sua tarefa de superador das incompletudes, incoerências e contradições das leis inferiores, em respeito ao estatuto maior. Nessa tarefa, os documentos internacionais, a exemplo da Convenção Americana de Direitos Humanos (CADH), ganham especial destaque ao interagir com o Texto Constitucional para o aperfeiçoamento de uma gama mais coesa de direitos fundamentais. Assim, ao se adotar a CADH como instrumento de consenso interamericano em torno dos direitos e garantias, fixa-se um marco de atuação dos diversos Estados e particulares na relação com os indivíduos e demais titulares, estabelecendo-se procedimentos para a solução de conflitos e, fundamentalmente, traçando-se os limites da atuação estatal.

Como pode ser percebido a partir dos diversos conceitos até então apresentados, o garantismo - nas palavras de Norberto Bobbio em prefácio à obra seminal de Luigi Ferrajoli, Direito e Razão - é um modelo ideal ao qual a realidade pode mais ou menos se aproximar. Como modelo representa uma meta que permanece até mesmo quando não é alcançada, e não pode ser nunca, de todo, alcançada. Mas para constituir uma meta, o modelo deve ser definido em todos os aspectos. 
Somente se for bem definido poderá servir também de critério de valoração e de correção do direito existente (FERRAJOLI, 2009, p. 9).

Difícil, entretanto, é modelar as técnicas legislativas e judiciais adequadas para assegurar efetividade aos princípios constitucionais e aos direitos fundamentais consagrados por eles. Streck e Saldanha (2013, p. 412) aduzem que:

o sistema jurídico por si só não pode garantir absolutamente nada; as garantias não podem estar sustentadas apenas em normas; nenhum Direito fundamental pode sobreviver concretamente sem o apoio da luta pela realização por parte de quem é seu titular e da solidariedade da força política e social.

Carvalho (2008, p. 102-103), muito embora reconheça que o modelo garantista assume um caráter ideal típico, afirma que este

[...] não se contenta com a mera proposição descritiva isenta de respaldo no plano da eficácia. [Por essa razão,] a proposta garantista nega os mitos do positivismo dogmático dedicados a uma visão meramente contemplativa de ordenamentos jurídicos absolutamente incapazes de responder às demandas das sociedades contemporâneas (complexas).

Partindo das premissas lançadas, Streck e Saldanha (2013, p. 413) lecionam que no Brasil o garantismo pode servir de importante mecanismo na construção das possibilidades para o resgate das promessas da modernidade. Com efeito, seria uma importante ferramenta para dar ao Judiciário condições de promover a efetividade do extenso rol de direitos fundamentais estabelecidos no Texto Constitucional, aproximando-se, assim, do cumprimento das promessas da modernidade. Por outro lado, o garantismo não pode se converter em uma panaceia para curar as deficiências do Estado Social, nem significa, principalmente em países periféricos, o retorno ao welfare state (que nunca existiu) (STRECK; SALDANHA, 2013, p. 413).

Apresentadas as notas paradigmáticas do garantismo, resta ressaltar as tarefas a serem desempenhadas por um ator jurídico que se pretenda garantista:

1) tutelar materialmente os direitos e garantias individuais e sociais (ROSA, 2003, p. 39), tanto por uma postura profissional dirigida à promoção e proteção dos direitos fundamentais (adotados como paradigma de atuação), quanto por uma difusão desse paradigma por meio da educação em direitos;

2) apresentar possibilidades de correção das situações de ausência de plenitude e incoerência do ordenamento jurídico, manejando os atributos das normas jurídicas, tendo em vista que estas não são desprovidas de conteúdo, fazendo a devida e impostergável oxigenação constitucional (ROSA, 2003, p. 72);

3) individualizar e ainda denunciar não somente as deformações do sistema jurídico positivo, assim compreendido o desenvolvimento hipertrófico do direito penal, ou ilu- 
são panpenalista, conforme aponta Norberto Bobbio, mas também desnudando todas aquelas situações nas quais permanecem poderes extrajurídicos, sobre os quais o Estado de Direito ainda não estendeu sua regra, e que, enquanto tais perpetuam relacionamentos de desigualdade, que têm recebido o nome sugestivo de "poderes selvagens" (FERRAJOLI, 2006, p. 12).

Mirando nessas tarefas, o defensor público, compreendendo o funcionamento do Sistema Interamericano de Direitos Humanos, pode se converter em importante instrumento de efetivação de uma visão garantista multinível, tendo por paradigma as normas constitucionais e convencionais protetivas de direitos humanos, na forma apresentada nas seguintes linhas.

\section{0 sistema interamericano de direitos humanos}

A Segunda Guerra Mundial representou um momento histórico gerador de profundas transformações. As atrocidades cometidas em nome da lei, em evidente afronta à dignidade humana, fizeram aflorar a necessidade da construção de um arcabouço jurídico pautado na universalização e internacionalização dos direitos humanos. $O$ documento basilar deste foi a Carta da Organização das Nações Unidas (ONU) (1945), aprovada na Conferência de São Francisco, em junho de 1945. A partir de então, construiu-se um sistema global de direitos humanos, em torno da ONU, seguindo-se a Declaração Universal dos Direitos Humanos de 1948 (ORGANIZAÇÃO DAS NAÇÕES UNIDAS, 1948), e diversos outros tratados.

Paralelamente, com a finalidade de reforçar o arcabouço internacional de proteção dos direitos humanos, levando-se em consideração as especificidades e afinidades regionais, surgiram os sistemas regionais de proteção dos direitos humanos, destacando-se o europeu, o africano e o interamericano. É sobre esse último, do qual o Brasil faz parte, que a investigação tratará.

Diversamente do sistema regional europeu, que teve como fonte inspiradora a tríade indissociável Estado de Direito, Democracia e Direitos Humanos, o sistema regional interamericano tem em sua origem o paradoxo de nascer em um ambiente acentuadamente autoritário (PIOVESAN, 2015, p. 145). Assim, o Sistema Interamericano de Direitos Humanos (SIDH) foi criado pela Organização dos Estados Americanos (OEA), em 1948. O primeiro documento a integrar o SIDH foi a Declaração Americana dos Direitos e Deveres do Homem (DADDH), proclamada em 1948; entretanto, o documento fundamental de proteção dos direitos humanos é a Convenção Americana sobre Direitos Humanos (CADH), de 1969, também chamada de Pacto de San Jose da Costa Rica, que entrou em vigor somente em 1978, após receber o número mínimo de 11 ratificações (MAZZUOLI, 2014, p. 114). Atualmente são 25 os Estados que aderiram e ratificaram a CADH, com ausências relevantes como EUA, Canadá e Venezuela, essa última tendo denunciado o Tratado em 2012. O Brasil aderiu à Convenção em 09 de julho de 1992, depositou a carta de adesão 
em 25 de setembro de 1992, promulgando-a por meio do Decreto n. 678, de 06 de novembro do mesmo ano (BRASIL, 1992).

A CADH assegura um catálogo de direitos civis e políticos, enquanto os direitos sociais, culturais e econômicos se encontram previstos no Protocolo de San Salvador (PSS), adicionado à CADH em 1988, e em vigor desde novembro de 1999. O Brasil ratificou o PPS em 1999, por meio do Decreto n. 3321, de 30 de dezembro de 1999 (BRASIL, 1999).

Conforme observa Mazzuoli (2014, p. 114-115), a proteção dos direitos humanos prevista na $\mathrm{CADH}$ é coadjuvante ou complementar da que oferece o Direito interno dos seus Estados-partes. Não se retira, pois, dos Estados a competência primária para amparar e proteger os direitos das pessoas sujeitas à sua jurisdição, mas que nos casos de falta de amparo ou de proteção aquém da necessária, em desconformidade com os direitos e garantias previstos na CADH, pode o SIDH atuar concorrendo para o objetivo comum de proteger determinado direito que o Estado não garantiu ou preservou menos do que deveria (MAZZUOLI, 2014, p. 115). É exatamente nessa perspectiva que se pensa, na esteira do proposto por Piovesan, ${ }^{3}$ em uma perspectiva garantista multinível de proteção de direitos no âmbito interno e, de forma complementar, pelo SIDH.

Cumpre lembrar, por oportuno, que a $\mathrm{CADH}$ passou a ostentar o status de norma supralegal no ordenamento jurídico brasileiro, conforme decisão do Supremo Tribunal Federal, ${ }^{4}$ que concedeu tal hierarquia aos tratados internacionais de direitos humanos não submetidos ao procedimento de incorporação ao direito interno estabelecido pelo $₫ 3^{\circ}$ do artigo $5^{\circ}$ da Constituição Federal de 1988 (CF/88), incluído pela Emenda Constitucional n. 45/2004 (BRASIL, 1988).

Disposição importante da $\mathrm{CADH}$ é a que estabelece a chamada "cláusula federal", cujo objetivo é impedir que os Estados aleguem questões internas relativas às competências de entes federativos para o descumprimento de normas da Convenção e posterior responsabilização. ${ }^{5}$

Em reforço à efetividade das normas contidas na $\mathrm{CADH}$, seu Artigo 29 estatui que nenhuma das suas disposições pode ser interpretada no sentido de:

\footnotetext{
3 Segundo Piovesan (2015, p.154), o SIDH gradativamente se empodera, mediante diálogos direcionados ao fortalecimento dos direitos humanos em um sistema multinível. É sob essa perspectiva multinível que emergem duas vertentes do diálogo jurisdicional, a compreender o diálogo com os sistemas nacionais (abrangendo o controle de convencionalidade) e o diálogo com a sociedade civil (conferindo ao SIDH crescente legitimação social).

4 No julgamento do RE 466.343, em 2006, o STF, ao decidir sobre a possibilidade de prisão civil do depositário infiel em face da proibição contida na $\mathrm{CADH}$, atribuiu status de norma supralegal aos tratados internacionais de direitos humanos não aprovados nos moldes fixados no art. $5^{\circ}, \$ 3^{\circ}$ da CF/88 (SUPREMO TRIBUNAL FEDERAL, 2009).

5 "Artigo 28. 1. Quando se tratar de um Estado-parte constituído como Estado federal, o governo nacional do aludido Estado-parte cumprirá todas as disposições da presente Convenção, relacionadas com as matérias sobre as quais exerce competência legislativa e judicial. 2. No tocante às disposições relativas às matérias que correspondem à competência das entidades componentes da federação, o governo nacional deve tomar imediatamente as medidas pertinentes, em conformidade com sua Constituição e com suas leis, a fim de que as autoridades competentes das referidas entidades possam adotar as disposições cabíveis para o cumprimento desta Convenção. 3. Quando dois ou mais Estados-partes decidirem constituir entre eles uma federação ou outro tipo de associação, diligenciarão no sentido de que o pacto comunitário respectivo contenha as disposições necessárias para que continuem sendo efetivas no novo Estado, assim organizado, as normas da presente Convenção" (ORGANIZAÇÃO DOS ESTADOS AMERICANOS, 1969).
} 
a) permitir a qualquer dos Estados-partes, grupo ou indivíduo, suprimir o gozo e o exercício dos direitos e liberdades reconhecidos na Convenção ou limitá-los em maior medida do que a nela prevista;

b) limitar o gozo e exercício de qualquer direito ou liberdade que possam ser reconhecidos em virtude de leis de qualquer dos Estados-partes ou em virtude de convenções em que seja parte um dos referidos Estados;

c) excluir outros direitos e garantias que são inerentes ao ser humano ou que decorrem da forma democrática representativa de governo;

d) excluir ou limitar o efeito que possam produzir a $\mathrm{DADH}$ e outros atos internacionais da mesma natureza (ORGANIZAÇÃO DOS ESTADOS AMERICANOS, 1969).

O monitoramento da efetividade dos direitos enunciados na $\mathrm{CADH}$ é levado a efeito pela Comissão Interamericana de Direitos Humanos (CIDH) e pela Corte Interamericana de Direitos Humanos (CorteIDH), nos moldes adiante estabelecidos.

A Comissão Interamericana de Direitos Humanos (CIDH) foi estabelecida na Carta da OEA, em 1948, e, por essa razão, sua competência alcança todos os Estados-membros da OEA, em relação aos direitos consagrados na $\mathrm{DADH}$ e às disposições contidas na $\mathrm{CADH}$ para o caso dos Estados que a ratificaram (PIOVESAN, 2013 p. 137). Sua configuração atual, entretanto, somente foi possível a partir do extenso rol de artigos da $\mathrm{CADH}$.

A CIDH, que atualmente tem sede em Washington (EUA), está composta de sete membros, pessoas de alta autoridade moral e de reconhecido saber em matéria de direitos humanos, que são eleitas, a título pessoal, pela Assembleia Geral da OEA, a partir de uma lista de candidatos propostos pelos governos dos Estados-membros, não podendo fazer parte da CIDH mais de um nacional de um mesmo Estado.

De acordo com o artigo 41 da CADH (ORGANIZAÇÃO DOS ESTADOS AMERICANOS, 1969), a Comissão tem a função principal de promover a observância e a defesa dos direitos humanos e, no exercício de seu mandato, tem as seguintes funções e atribuições: estimular a consciência dos direitos humanos nos povos da América; formular recomendações aos governos dos Estados-membros, quando considerar conveniente, no sentido de que adotem medidas progressivas em prol dos direitos humanos no âmbito de suas leis internas e seus preceitos constitucionais, bem como disposições apropriadas para promover o devido respeito a esses direitos; preparar estudos ou relatórios que considerar convenientes para o desempenho de suas funções; solicitar aos governos dos Estados-membros que the proporcionem informações sobre as medidas que adotarem em matéria de direitos humanos; atender às consultas que, por meio da Secretaria Geral da Organização dos Estados Americanos, lhe formularem os Estados-membros sobre questões relacionadas com os direitos humanos e, dentro de suas possibilidades, prestar-lhes o assessoramento que lhes solicitarem; atuar com respeito às petições e outras comunicações, no exercício de sua autoridade, 
de conformidade com o disposto nos artigos 44 a 51 desSa Convenção; e apresentar um relatório anual à Assembleia Geral da OEA.

O acesso à CIDH é amplo, pois, conforme o artigo 44 (ORGANIZAÇÃO DOS ESTADOS AMERICANOS, 1969), qualquer pessoa ou grupo de pessoas, ou entidade não governamental legalmente reconhecida em um ou mais Estados-membros da OEA, pode apresentar à CIDH petições que contenham denúncias ou queixas de violação da $\mathrm{CADH}$ por um Estado-parte, desde que cumpridos os requisitos de admissibilidade encartados no seu artigo 46.

Detalhe importante é que somente a CIDH e os Estados-partes podem submeter um caso à CorteIDH, conforme disposto nos artigos 57 e 61, respectivamente (ORGANIZAÇÃO DOS ESTADOS AMERICANOS, 1969), não estando legitimados o indivíduo, grupos de indivíduos ou organizações não governamentais (PIOVESAN, 2013, p. 143). Por essa razão, a doutrina considera o papel da CIDH assemelhado ao desempenhado pelo Ministério Público no sistema de justiça brasileiro, no tocante às ações penais de iniciativa pública incondicionada.

Já a CorteIDH tem sede atual em San José da Costa Rica, local de assinatura da CADH, embora possa realizar reuniões no território de qualquer Estado-membro da OEA em que considerar conveniente, pela maioria dos seus membros e mediante prévia aquiescência do Estado respectivo, conforme o artigo 58 da CADH (ORGANIZAÇÃO DOS ESTADOS AMERICANOS, 1969). É composta de sete juízes, nacionais dos Estados-membros da OEA, eleitos a título pessoal dentre juristas da mais alta autoridade moral, de reconhecida competência em matéria de direitos humanos.

A CorteIDH é competente para processar e julgar qualquer caso relativo à interpretação e à aplicação das disposições da $\mathrm{CADH}$, para apreciar consultas dos Estados relativas à interpretação das normas do SIDH e para emitir pareceres a respeito da compatibilidade entre leis internas e os tratados do SIDH, o que vem sendo chamado de controle de convencionalidade.

Hoje são 20 Estados submetidos à sua jurisdição contenciosa. Mencione-se, mais uma vez, importantes ausências: EUA, Canadá e Venezuela. O Estado brasileiro reconheceu a jurisdição contenciosa da Corte IDH por meio do Decreto n 4.463, de 08 de novembro de 2002, para o julgamento de fatos posteriores a 10 de dezembro de 1998 (BRASIL, 2002). A submissão à jurisdição de uma Corte internacional não significa um enfraquecimento da soberania estatal, mas o fortalecimento de sua democracia e da promoção dos direitos fundamentais elencados na sua Constituição (LASCALA; FREITAS, 2012, p. 1040).

Ressalte-se que a Corte não efetua uma interpretação estática dos direitos humanos enunciados na $\mathrm{CADH}$, mas, como a Corte Europeia, realiza interpretação dinâmica e evolutiva, considerando o contexto temporal e as transformações sociais, o que permite a expansão de direitos (PIOVESAN, 2013, p. 146).

Streck e Saldanha (2013, p. 415) ressaltam a importância da jurisprudência da CorteIDH para a consolidação dos direitos humanos na América Latina, subcontinente marcado por Estados 
submetidos a governos autoritários que, ao longo de décadas, não só reforçaram as consequências negativas do pós-colonialismo e institucionalizaram a violência, mas também cumpriram a agenda econômica neoliberal predeterminada. Ademais, outra importante contribuição da CorteIDH para o direito internacional dos direitos humanos tem sido a imposição bem-sucedida de reparações, não mais limitadas ao pagamento de indenizações, mormente no que se refere às alterações legislativas necessárias para compatibilizar o direito interno à $\mathrm{CADH}$.

A principal dificuldade que a CorteIDH vem enfrentando se refere ao cumprimento das condenações referentes às investigações efetivas dos fatos que originaram as violações, bem como a identificação e sanção dos responsáveis. De fato, como preconiza Bobbio (1992, p. 25), a garantia dos direitos humanos no plano internacional será implementada somente quando uma "jurisdição internacional se impuser concretamente sobre as jurisdições nacionais, deixando de operar dentro dos Estados, mas contra os Estados e na defesa do cidadão." Piovesan (2013, p. 163-166) aponta alguns caminhos para o fortalecimento da justiça internacional:

a) adoção de legislação interna, pelos Estados, relativa à implementação das decisões internacionais em matéria de diretos humanos;

b) previsão de sanção ao Estado que, de forma reiterada e sistemática, descumprir as decisões internacionais;

c) demanda por maior democratização do sistema, começando com o direito de acesso direto do indivíduo à CorteIDH;

d) instituição de funcionamento permanente e da $\mathrm{CIDH}$ e da CorteIDH, com recursos financeiros, técnicos e administrativos suficientes.

Entretanto, enquanto tais medidas não são implementadas, é possível valer-se da simbiose existente entre a ordem constitucional interna e os organismos internacionais, potencializando a proteção dos direitos humanos. De fato, como leciona Neves (2014, p. 207), o caminho mais adequado em matéria de direitos humanos parece ser o "modelo de articulação" (engagement model) ou melhor, de entrelaçamento transversal entre ordens jurídicas, de tal maneira que todas se apresentem capazes de se reconstruírem permanentemente mediante o aprendizado com as experiências de ordens jurídicas interessadas concomitantemente na solução dos mesmos problemas jurídicos constitucionais de direitos fundamentais ou direitos humanos.

O objetivo com este trabalho, portanto, é investigar como a Defensoria Pública pode funcionar como instituição catalisadora desse "modelo de articulação" entre ordens jurídicas, resultando em um ambiente de maior conhecimento, promoção e proteção de direitos humanos. 


\section{Atuação da defensoria pública na defesa de direitos humanos}

A Constituição Federal de 1988 (CF/88), resultado de um compromisso entre as forças sociais dominantes no período pós-ditadura militar, representa o marco normativo da resignificação das constituições em terras brasileiras, promovendo profundas alterações na forma de interpretar e aplicar o Direito, reaproximando-o da moral e entronizando a dignidade da pessoa humana como princípio fundamental, submetendo à sua observância toda a atividade estatal. Como defende Silva (2001, p. 29), a CF/88 representa o principal momento da reconstrução das instituições democráticas do Estado.

Nesse contexto, o rol de direitos fundamentais foi expressivamente ampliado, ganhando destaque a criação da Defensoria Pública, como instituição destinada a prestar assistência jurídica integral e gratuita aos que comprovarem insuficiência de recursos, ${ }^{6}$ de forma a garantir a proteção desses direitos.

poder constituinte derivado, por sua vez, ampliou o raio de ação e as condições estruturais da Defensoria Pública, por meio de emendas constitucionais, consolidando-a como Instituição promotora do acesso à justiça e de proteção dos direitos fundamentais, mormente da população vulnerável. Com efeito, a Emenda Constitucional n. 45/2004 foi fundamental para o fortalecimento de autonomia funcional e administrativa, além de garantir a iniciativa de proposta orçamentária às Defensorias Públicas Estaduais. ${ }^{7}$ Já a Emenda Constitucional n. 80/2014, além de prever a simetria de tratamento dada aos membros do Judiciário, no que couber dos artigos 93 e 96, II da Constituição, estabeleceu expressamente, na nova redação dada ao artigo 134, que à Defensoria Pública cabe, como expressão e instrumento do regime democrático, a orientação jurídica, a promoção dos direitos humanos e a defesa, em todos os graus, judicial e extrajudicial, dos direitos individuais e coletivos, de forma integral e gratuita, aos necessitados, na forma do inciso LXXV do art. 75 da CF/88 (BRASIL 1988).

Da mesma forma, a Lei Orgânica da Defensoria Pública - Lei Complementar n. 80/1994 (BRASIL, 1994), cuja redação foi alterada significativamente em 2009, com a Lei Complementar n. 132/2009, estatui em seu artigo $3^{\circ}$-A que são objetivos da Defensoria Pública: a primazia da dignidade da pessoa humana e a redução das desigualdades sociais; a afirmação do Estado Democrático de Direito; a prevalência e efetividade dos direitos humanos; e a garantia dos princípios constitucionais da ampla defesa e do contraditório. Já no artigo $4^{\circ}$, III do mesmo diploma legal, são funções insti-

\footnotetext{
6 A redação original do art. 134 da CF/88, era a seguinte: "A Defensoria Pública é instituição essencial à função jurisdicional do Estado, incumbindo-lhe a orientação jurídica e a defesa, em todos os graus, dos necessitados, na forma do art. $5^{\circ}$, LXXIV." (BRASIL 1988).

7 Art. 134 [...] $\$ 2^{\circ}$ Às Defensorias Públicas Estaduais são asseguradas autonomia funcional e administrativa e a iniciativa de sua proposta orçamentária dentro dos limites estabelecidos na lei de diretrizes orçamentárias e subordinação ao disposto no art. 99, $\mathbb{\$} 2^{\circ}$ (BRASIL 1988).
} 
tucionais da Defensoria Pública, dentre outras, promover a difusão e a conscientização dos direitos humanos, da cidadania e do ordenamento jurídico.

Por fim, importante a construção de um novo paradigma de atuação da Defensoria Pública na defesa dos direitos humanos, com ênfase em seis grandes eixos:

1) atuação judicial clássica, ou seja, como instância de proteção e defesa dos vulneráveis na esfera judicial;

2) educação em direitos para o empoderamento dos vulneráveis, para a garantia do seu efetivo exercício;

3) atuação metaindividual, por meio da proteção de direitos coletivos em sentido amplo, almejando a concretização dessa "segunda onda de acesso à justiça", na classificação pensada por Cappelletti e Garth (1988, p. 49), com expressiva vantagem sobre as repetitivas demandas individuais;

4) atuação extrajudicial, aparecendo como instituição vocacionada aos meios democráticos de solução dos conflitos (mediação, conciliação, arbitragem);

5) pioneirismo da previsão de uma ouvidoria externa, apta a aprofundar as discussões referentes à atuação da Defensoria Pública, a partir do discurso oriundo da sociedade, sendo capaz, portanto, de funcionar como instituição captadora das ofensas aos direitos humanos;

6) atuação internacional nos sistemas internacionais de proteção de direitos humanos, a exemplo do Sistema Interamericano, como será exposto na seção que segue.

\section{Atuação da defensoria pública no sistema interamericano de direitos humanos}

O crescente fortalecimento dos sistemas internacionais de proteção dos direitos humanos vem exigindo que os Estados moldem as atuações das suas instituições internas de forma a viabilizar seu acesso aos órgãos de monitoramento do cumprimento das normas de proteção desses direitos, possibilitando a convivência dialógica entre os sistemas jurídicos internos e os internacionais. Como observa Neves (2014, p. 211), uma transformação profunda tem ocorrido, nas condições hodiernas da sociedade mundial, no sentido da superação do constitucionalismo provinciano ou paroquial pelo transconstitucionalismo, inclusive na América Latina. O Estado deixou de ser um locus provilegiado de solução de problemas constitucionais. Embora fundamental e indispensável, é apenas um dos diversos loci em cooperação e concorrência na busca do tratamento desses problemas. A integração sistêmica cada vez maior da sociedade mundial tem provocado a desterritorialização de problemas-caso jurídico-constitucionais, que, por assim dizer, emanciparam-se do Estado (NEVES, 2014, p. 211).

Isto é, aos parâmetros constitucionais somam-se os parâmetros convencionais, na composição de um trapézio jurídico aberto ao diálogo, aos empréstimos e à interdisciplinariedade, a 
resignificar o fenômeno jurídico sob a inspiração do human rights aproach (PIOVESAN, 2015, p. 155). Deve-se buscar, desse modo, uma "interpretação interativa", no dizer de Steiner (2000, p. 112), já que a Convenção Americana de Direitos Humanos (CADH), por exemplo, explicita muitos dos dispositivos constitucionais.

Desde o reconhecimento da competência contenciosa da CorteIDH, o diálogo entre ela e o Estado brasileiro vem se fortalecendo cada vez mais, como apontam Lascala e Freitas (2012, p. 117): O Brasil apresenta defesa escrita e oral nas audiências da CorteIDH; designa representantes do governo para atuarem como autoridades responsáveis pelo Estado nessas audiências; há projetos de lei da Câmara e do Senado Federal sobre o modo de cumprimento das sentenças da CorteIDH; há pareceres jurídicos favoráveis ao cumprimento de suas decisões pela Advocacia-Geral da União, notadamente nas consultorias jurídicas dos Ministérios da Justiça, das Relações Exteriores e do Ministério dos Direitos Humanos; há decisões judiciais em todas as instâncias, inclusive no STF, reconhecendo o status constitucional dos tratados de direitos humanos, como o Pacto de San José da Costa Rica; a Secretaria Especial de Direitos Humanos, órgão equiparado a um Ministério do Poder executivo Federal, possui competência para conduzir o cumprimento das sentenças da CorteIDH.

Nesse diálogo entre cortes, urge definir o papel da Defensoria Pública, alçada pela CF/88 à condição de instituição promotora dos direitos humanos. Inicialmente, é importante que os defensores públicos, na sua labuta diuturna, passem a utilizar de forma maciça, nas suas peças e manifestações jurídicas ordinárias, cotidianas, os documentos internacionais de direitos humanos e a jurisprudência emanada da Comissão Interamericana de Direitos Humanos (CIDH) e da CorteIDH, fazendo referência a interpretações, decisões, opiniões consultivas e informes emitidos (LEITE, 2014, p. 578).

Essa forma de atuação, além de chamar a atenção para direitos estatuídos como consenso no continente, reforçando, assim, a importância de sua efetividade, deriva do chamado controle de convencionalidade, que pode ser definido como a obrigação que juízes e outras autoridades nacionais têm de "inaplicar aquellas normas domésticas que no se conforman con las cláusulas de la Convención Americana sobre Derechos Humanos, así como la interpretación que de éstas hace la misma Corte." (CONTESSE, 2013).

Esse controle foi instituído pela CorteIDH no caso Almonacid Arellano e outros vs. Chile, em 2006 (CORTE INTERAMERICANA DE DIREITOS HUMANOS, 2006). Nesse caso, o Estado chileno foi condenado por não ter investigado e sancionado os responsáveis pelo assassinato cometido por carabineros contra Luis Alfredo Almonacid Arellano no dia 16 de setembro de 1973. A vítima, de 42 anos, era professor de ensino fundamental e militante do Partido Comunista do Chile. $\bigcirc$ crime não foi investigado porque os autores foram beneficiados pelo Decreto Lei n. 2.191, de 11 de abril de 1978 (CHILE, 1978), que anistiou todas as pessoas envolvidas em fatos criminosos dessa natureza cometidos entre 11 de setembro de 1973 e 10 de março de 1978. 
$\mathrm{Na}$ sentença, a CorteIDH entendeu que, apesar de existir uma lei interna que concedia anistia aos autores desse tipo de crime, o Estado chileno tinha antes a obrigação de respeitar as normas da $\mathrm{CADH}$ :

124. La Corte es consciente que los jueces y tribunales internos están sujetos al imperio de la ley y, por ello, están obligados a aplicar las disposiciones vigentes en el ordenamiento jurídico. Pero cuando un Estado ha ratificado un tratado internacional como la Convención Americana, sus jueces, como parte del aparato del Estado, también están sometidos a ella, lo que les obliga a velar porque los efectos de las disposiciones de la Convención no se vean mermadas por la aplicación de leyes contrarias a su objeto y fin, y que desde un inicio carecen de efectos jurídicos. En otras palabras, el Poder Judicial debe ejercer una especie de "control de convencionalidad" entre las normas jurídicas internas que aplican en los casos concretos y la Convención Americana sobre Derechos Humanos. En esta tarea, el Poder Judicial debe tener en cuenta no solamente el tratado, sino también la interpretación que del mismo ha hecho la Corte Interamericana, intérprete última de la Convención Americana. (CORTE INTERAMERICANA DE DIREITOS HUMANOS, 2006).

Verifica-se, portanto, a existência da obrigação de juízes e outras autoridades dos Estados que ratificaram a $\mathrm{CADH}$ de efetivamente aplicá-la no âmbito interno. Desse modo, os defensores públicos nacionais são também, agora, defensores públicos interamericanos, na medida em que devem arguir e provocar o exercício desse controle por parte dos juízos e tribunais, na aplicação do Direito ao caso concreto. Do mesmo modo, cabe à Defensoria provocar os legitimados para propor as ações diretas de inconstitucionalidade para que questionem no STF as normas internas contrárias à $\mathrm{CADH}$.

Ademais, quando restarem insuficientes as instituições internas para a proteção dos direitos humanos convencionais vilipendiados, caberia à Defensoria Pública denunciar o Estado brasileiro perante a CIDH para que, diretamente ou acionando a CorteIDH, defenda-os. Impende lembrar que a Lei Complementar n. 80/1994, em seu artigo 4º, VI, estatui que é função institucional da Defensoria Pública, entre outras, representar os sistemas internacionais de proteção dos direitos humanos, postulando perante seus órgãos (BRASIL, 1994).

Assim agindo, cumprirá a Defensoria Pública importante papel de efetivação do chamado transconstitucionalismo, que implica, conforme os ensinamentos de Neves (2014, p. 211), o reconhecimento de que as diversas ordens jurídicas entrelaçadas na solução de um problema-caso constitucional - a saber, de direitos fundamentais ou humanos e de organização legítima do poder -, que lhes seja concomitantemente relevante, devem buscar formas transversais de articulação para a solução do problema, cada uma delas observando a outra, para compreender os seus próprios limites e possibilidades de contribuir para solucioná-lo. Sua identidade é reconstruída, dessa maneira, enquanto levada a sério a alteridade, a observação do outro (NEVES, 2014, p. 211). Permite-se, assim, a construção de um constitucionalismo regional transformador, um "Ius Constitucionale Commune Latino Americano" em matéria de direitos humanos (PIOVESAN, 2015, p. 144).

Além da atuação judicial clássica baseada nos tratados interamericanos, a Defensoria Pública pode funcionar como instituição difusora dessas convenções, mormente a $\mathrm{CADH}$, seja no sis- 
tema de justiça, seja por meio da educação em direitos, outro papel importante a ser desempenhado e que consiste no empoderamento de pessoas e comunidades, especialmente as mais carentes, esclarecendo sobre a existência e relevância dos tratados internacionais, além de produzir estratégias de apresentação de casos à $\mathrm{CIDH}$.

Importante lembrar que $100 \%$ dos casos submetidos à $\mathrm{CIDH}$ foram fruto de uma articulação que reuniu vítimas e organizações não governamentais locais e internacionais, com intenso protagonismo na seleção de um caso paradigmático, na litigância deste (aliando estratégias jurídicas e políticas) e na implementação doméstica de eventuais ganhos internacionais (PIOVESAN, 2015, p. 158). Essa atuação da sociedade civil já foi destacada por Piovesan (2015, p. 144) ao defender que o sistema interamericano tem tido a força catalisadora de promover avanços no regime de direitos humanos, com a atuação da sociedade civil, a partir de articuladas e competentes estratégias de litigância. Assim, permitiu a desestabilização de regimes ditatoriais, exigiu justiça e o fim da impunidade nas transições democráticas, e agora demanda o fortalecimento das instituições democráticas com o necessário combate às violações de direitos humanos e proteção aos grupos mais vulneráveis (PIOVESAN, 2015, p. 144).

É inegável a potencialidade da Defensoria Pública de protagonizar essa atuação atualmente desempenhada por organizações não governamentais. Isso porque há uma estrutura institucional que pode servir de suporte para a capacitação de defensores públicos de núcleos de direitos humanos especializados, além da natural proximidade desses profissionais com as comunidades mais carentes, nas quais certamente são diuturnas as violações a direitos humanos, aptas a gerar a provocação do Sistema Interamericano.

Essa atuação ganha importância ainda mais elevada se o caso apresentado chega a merecer a apreciação da CorteIDH, porque o ônus argumentativo para rejeitar suas decisões é enorme (SILVA, 2010, p. 111) e, por outro lado, em razão da amplitude dos efeitos da decisão dessa Corte internacional que, como leciona Hitters (2014, p. 360), originam dois tipos de consequência: vinculação direta e obrigatória para o Estado condenado e vinculação relativa - erga omnes - para todos os membros do modelo que não participaram do processo.

No mesmo diapasão, doutrina Falconí (2011, p. 283) que as decisões do SIDH (especialmente da CorteIDH) devem ser consideradas vinculantes e de aplicação obrigatória por todos os juízes nacionais, tendo, portanto, a obrigação de aplicar o controle de convencionalidade na resolução dos casos postos à sua consideração, o que implica adequar as normas do direito interno inclusive as de nível constitucional, à $\mathrm{CADH}$.

Em última análise, pois, cumpre-se em sua integralidade a sentença de que o defensor público nacional é também um defensor interamericano, ao possibilitar, a partir de sua atuação pontual, provocar o Sistema Interamericano, mediante a obtenção de uma decisão da CorteIDH que servirá de paradigma de atuação dos Estados signatários da $\mathrm{CADH}$, independentemente da partici- 
pação no processo. Isso porque a jurisprudência da CorteIDH passa a compor, como já dito alhures, o paradigma interamericano de proteção dos direitos humanos.

Leite (2014, p. 579-580) faz referência, ainda, ao chamado "efeito bumerangue" do funcionamento do SIDH. Segundo ele, a apresentação de uma denúncia nesse Sistema provoca, regressivamente, no Estado de origem, uma movimentação dos órgãos e instituições envolvidos no caso, a fim de evitar que a denúncia tenha seguimento e que, nalgum momento, esses órgãos e instituições sejam apontados como violadores de direitos humanos (LEITE, 2014, p. 579-580). Destaque-se, portanto, o caráter pedagógico causado pela simples movimentação do sistema interamericano, a provocar nos Estados uma tentativa de correção de rumos, como forma de evitar o desgaste e a má impressão internacionais, inevitavelmente causados pelo descumprimento de direitos humanos.

Há que se lembrar, todavia, que mesmo com a previsão de mecanismos de responsabilização por violações aos direitos humanos e com a instituição da CorteIDH como órgão judicial internacional, a efetiva proteção dos direitos humanos previstos na $\mathrm{CADH}$ ainda depende da existência de instrumentos de execução interna das decisões proferidas pela CorteIDH, pois inexistem institutos jurídicos que viabilizem a substituição da vontade do Estado violador pela vontade de cortes internacionais, mesmo nos casos dos Estados que reconheçem a sua jurisdição obrigatória (BOCATTO, 2015, p. 388). Como lembra Herencia Carrasco (2011, p. 388), a CorteIDH não tem mecanismos coercitivos para fazer efetivo o cumprimento de suas sentenças, dependendo do princípio de boa-fé dos Estados no seu compromisso com suas obrigações internacionais.

Não se olvida que, em caso de descumprimento da decisão da CorteIDH, cabe a esta informar tal fato à Assembleia-Geral da Organização dos Estados Americanos (OEA), no relatório que todo ano deve apresentar a esse órgão, fazendo as recomendações pertinentes. Ocorre que, na prática, a Assembleia-Geral da OEA, infelizmente, nada tem feito a fim de exigir dos Estados condenados pela CorteIDH o efetivo cumprimento das sentenças de reparação ou ressarcimento (MAZZUOLI, 2014, p. 124).

Na busca de alternativas a esse problema, deve-se lembrar, contudo, que a decisão condenatória proferida pela CorteIDH deve ser classificada como sentença internacional. Ela não se confunde com a sentença estrangeira, que é aquela que necessita de homologação pelo Superior Tribunal de Justiça (STJ) para ser executada no Brasil, conforme o artigo 105, I, i da CF/88 (BRASIL, 1988). Na medida em que a sentença estrangeira é proferida por outro Estado soberano, o STJ deve verificar se ofende ou não a soberania nacional e a ordem pública (LASCALA; FREITAS, 2012, p. 105).

A propósito, a $\mathrm{CADH}$, em seu artigo 68.2, estabelece que a parte da sentença que determinar uma indenização compensatória à vítima poderá ser executada pelo respectivo Estado por intermédio do processo interno comum de execução de sentenças contra o Estado. No caso de outras obrigações de fazer e não fazer, Bocatto (2015, p. 403) defende que poderão ser judicialmente exigidas ao Estado seja por demanda da própria vítima, seja por ação ajuizada pelo Ministério Público Federal, sendo possível invocar a legislação processual civil referente à execução de obrigações man- 
damentais e de entregar a coisa certa. Quanto às obrigações de investigar, apurar fatos, punir agentes infratores, revogar leis violadoras dos direitos humanos, anular decisões judiciais, ainda será possível à vítima requerer a conversão em perdas e danos (BOCATTO, 2015, p. 403).

Como pode ser percebido, existem mecanismos, no ordenamento jurídico interno de execução das decisões da CorteIDH, embora se reconheça a necessidade de reforçar esses instrumentos, para garantir a integral exigibilidade das decisões internacionais em matéria de direito humanos. Piovesan (2013, p. 116) sugere, por exemplo, a suspensão ou expulsão do Estado da Assembleia Geral da OEA em caso de reiterado e sistemático descumprimento das decisões da CorteIDH.

Nesse particular, como instituição responsável pela assistência jurídica integral e gratuita aos hipossuficientes, a Defensoria Pública deve ser a instituição a quem as vítimas de violação de direitos humanos podem recorrer para tornar efetivas as decisões da CorteIDH, valendo-se dos citados instrumentos do direito interno, ou, em última análise, provocando novamente o Sistema Interamericano, via $\mathrm{CIDH}$, para que se manifeste sobre o descumprimento.

De fato, como adverte Piovesan (2015, p. 159), é também fundamental fortalecer a efetividade do Sistema Interamericano no que se refere à supervisão das decisões da CorteIDH ou CIDH, pois, diversamente do Sistema Europeu, não há mecanismo específico para tal tarefa, cabendo aos próprios órgãos o follow up das decisões que eles próprios proferem. Abre-se aqui mais um nicho de atuação possível da Defensoria Pública, a saber, na fiscalização e acompanhamento do cumprimento das decisões dos órgãos do Sistema Interamericano, valendo-se, para isso, dos mecanismos internos e mesmo acessando novamente o próprio Sistema Interamericano, se necessário, haja vista que, conforme doutrina Pellegrini (2011, p. 102), o descumprimento de decisões da CorteIDH representa um "nuevo ilícito internacional".

Outra função importante a ser desempenhada pela Defensoria Pública é a obrigação de apoiar iniciativas de implementação da $\mathrm{CADH}$. Nesse tocante, refere-se à previsão das audiências de custódia, projeto idealizado pelo Conselho Nacional de Justiça (CNJ) que determina a obrigatoriedade de apresentação do preso, sem demora, à autoridade judiciária, em cumprimento ao estatuído no artigo 5.7 da $\mathrm{CADH}^{8}$ (CONSELHO NACIONAL DE JUSTIÇA, 2015). De fato, tal iniciativa recebeu intensa resistência, mormente de órgãos ligados à persecução penal, merecendo no Ceará, a título de exemplo, nota técnica por sua inconstitucionalidade por parte do Ministério Público estadual (ASSOCIAÇÃO CEARENSE DO MINISTÉRIO PÚBLICO, 2015). Cabe à Defensoria Pública, portanto, o papel de contrapor-se a esse discurso, funcionando como instância de pensamento e ação garantidora da efetivação da $\mathrm{CADH}$, seja valendo-se dos fóruns de discussão próprios, seja pela utilização dos meios judiciais necessários.

\footnotetext{
$\overline{8}$ "Artigo 7 - Liberdade pessoal [...] 5. Toda pessoa presa, detida ou retida deve ser conduzida, sem demora, à presença de um juiz ou outra autoridade autorizada por lei a exercer funções judiciais e tem o direito de ser julgada em prazo razoável ou de ser posta em liberdade, sem prejuízo de que prossiga o processo. Sua liberdade pode ser condicionada a garantias que assegurem o seu comparecimento em juízo." (ORGANIZAÇÃO DOS ESTADOS AMERICANOS, 1969).
} 
Por fim, urge destacar a possibilidade de participação da Defensoria Pública como amicus curiae nos processos em trâmite na CorteIDH. Como cediço, a vítima ou organização denunciante não tem acesso direto à CorteIDH, posto que somente a CIDH e os Estados-partes podem acessá-la. Entretanto, o regulamento da CorteIDH, em seu artigo 44 (ORGANIZAÇÃO DOS ESTADOS AMERICANOS, 2009), prevê a figura do amicus curiae, cabendo perfeitamente a atuação da Defensoria Pública nesse particular, especialmente porque poderá subsidiar na compreensão do contexto social em torno da violação perpetrada.

\section{Conclusão}

Apesar da existência de uma grande quantidade de diplomas legais nacionais e internacionais de proteção de direitos humanos, perseveram, ainda hoje, as mais abjetas formas de violação, seja pela atuação dos Estados seja dos particulares. Diante desse panorama, verifica-se a necessidade de se adotar uma perspectiva do Direito capaz de oferecer os subsídios teóricos e práticos necessários para garantir efetivamente os direitos humanos.

A perspectiva que, no presente trabalho, propõe-se que seja adotada é a garantista, nos moldes propostos por Ferrajoli (2006), embora com alguns novos matizes. O garantismo vem hoje ganhando novos contornos decorrentes da superação do constitucionalismo nacional por um transconstitucionalismo (NEVES, 2014, p. 211). Trata-se de um modelo garantista multinível de direitos humanos, que contempla as disposições constitucionais dos Estados e as disposições convencionais dos sistemas internacionais, em um rico e permanente diálogo.

Nesse diapasão, é crescente a importância do Sistema Interamericano de Direitos Humanos (SIDH), em uma região de histórico recente de autoritarismo e ainda refém de graves violações de direitos humanos. $O$ consenso em torno da necessidade de efetivação do princípio da dignidade humana, que perpassa a Convenção Americana de Direitos Humanos (CADH), vem permeando a atuação dos Estados americanos. Assim, o cumprimento da promessa garantista não mais se efetiva com a simples (mas não menos importante) observância das normas nacionais, mas pressupõe o crivo do monitoramento da Comissão Interamericana de Direitos Humanos (CIDH) e da Corte Interamericana de Direitos Humanos (CorteIDH), comprometidos com a construção de um "Ius Constitucionale Commune Latino-Americano" em matéria de direitos humanos (PIOVESAN, 2015, p. 144).

Com o olhar partindo do âmbito nacional em direção à consolidação desse consenso, destaca-se a Defensoria Pública como a instituição brasileira desenhada constitucionalmente para a proteção dos direitos humanos e cuja atuação deve ser pautada por uma perspectiva garantista multinível de direitos constitucionais e convencionais.

Nesse sentido, no âmbito nacional, é mister que, em primeiro lugar, a Defensoria Pública cumpra, efetivamente, o papel de promotora dos direitos humanos, mediante sua atuação tutelar clássica, extrajudicial, educação em direitos e tutela metaindividual. 
Segundo, a Defensoria deve também promover o controle de convencionalidade na labuta diuturna de acesso ao Judiciário, a partir da arguição dos documentos interamericanos de direitos humanos e das decisões da CIDH e da CorteIDH, exigindo a adequação do ordenamento jurídico nacional aos seus ditames. Essa forma de atuação chama a atenção para esses direitos, que foram estatuídos de forma consensual no continente, reforçando, assim, a importância de sua efetividade. Agindo dessa maneira, os defensores públicos converter-se-ão em autênticos defensores interamericanos de direitos humanos.

Terceiro, quando restarem insuficientes as instituições internas para a proteção dos direitos humanos convencionais vilipendiados, cabe à Defensoria Pública provocar a CIDH para que exerça tal controle diretamente ou acionando a CorteIDH. De fato, a Lei Complementar n. 80/1994, em seu artigo $4^{\circ}$, VI, estatui que é função institucional da Defensoria Pública, entre outras, representar aos sistemas internacionais de proteção dos direitos humanos, postulando perante seus órgãos (BRASIL, 1994).

Quarto, a Defensoria Pública pode funcionar como instituição difusora das normas do $\mathrm{SIDH}$, mormente a $\mathrm{CADH}$, seja no sistema de justiça, seja por meio da educação em direitos, outro papel importante a ser desempenhado e que consiste no empoderamento de pessoas e comunidades, especialmente as mais carentes, esclarecendo sobre a existência e relevância dos tratados internacionais, além de produzir estratégias de apresentação de casos à $\mathrm{CIDH}$.

Em quinto lugar, inegável a potencialidade da Defensoria Pública de protagonizar o acesso à CIDH, função atualmente desempenhada por organizações não governamentais. Isso porque há uma estrutura institucional que pode servir de suporte para a capacitação de defensores públicos de núcleos de direitos humanos especializados, além da natural proximidade desses profissionais com as comunidades mais carentes, nas quais certamente são diuturnas as violações a direitos humanos, aptas a gerar a provocação do Sistema Interamericano. Ademais, a partir de sua atuação pontual de provocar o SIDH, a obtenção de uma decisão da CorteIDH servirá de paradigma de atuação dos Estados signatários da $\mathrm{CADH}$, independentemente da sua participação no processo. Isso porque a jurisprudência da CorteIDH passa a compor, como já dito alhures, o paradigma interamericano de proteção dos direitos humanos.

Em sexto, a atuação da Defensoria Pública pode provocar o chamado "efeito bumerangue" do funcionamento do SIDH, na medida em que a apresentação de uma denúncia a tal Sistema provoca, regressivamente, no Estado de origem, uma movimentação dos órgãos e instituições envolvidos no caso, a fim de evitar que a denúncia tenha seguimento e que, em algum momento, esses órgãos e instituições sejam apontados como violadores de direitos humanos (LEITE, 2014, p. 579-580).

Em sétimo lugar, a Defensoria Pública, como instituição responsável pela assistência jurídica integral e gratuita aos hipossuficientes, deve ser buscada pelas vítimas de violação a direitos humanos para tornar efetivas as decisões da CorteIDH, valendo-se dos citados instrumentos do direito 
interno para a execução das sentenças, ou, em última análise, provocando novamente o SIDH, via $\mathrm{CIDH}$, para que se manifeste sobre o descumprimento.

Em oitavo lugar, pode-se atribuir à Defensoria Pública a tarefa de fiscalização e acompanhamento do cumprimento das decisões dos órgãos do sistema interamericano (follow up), pois, diversamente do sistema europeu, não há mecanismo específico para tal tarefa, cabendo aos próprios órgãos prolatores o acompanhamento de suas decisões. Para tanto, é possível valer-se dos mecanismos internos ou mesmo acessando novamente o sistema interamericano, se necessário, como já defendido.

Como nona relevante função a ser desempenhada pela Defensoria Pública, emerge a obrigação de apoiar iniciativas de implementação da $\mathrm{CADH}$, ainda que estas sofram resistências de setores comprometidos com um Estado cada vez mais repressor.

Por fim, urge destacar a possibilidade de participação da Defensoria Pública como amicus curiae nos processos em trâmite na CorteIDH, contribuindo, por exemplo, na compreensão das circunstâncias fático-valorativas em torno do caso concreto.

Obviamente que não se atribui à Defensoria Pública o papel de redentora dos direitos humanos e de panaceia para a superação dos obstáculos de funcionamento do SIDH. Suas deficiências estruturais ainda são gigantescas, e as tarefas cotidianas no exercício das funções corriqueiras já absorvem a maior parte da energia e atenções dos defensores púbicos, ainda muito poucos para tão ingentes desafios. No entanto, é importante explorar as potencialidades da mais jovem das instituições jurídicas em direção à sua consolidação como porta de acesso à Justiça e de inclusão social, via efetividade dos direitos humanos, sua mais nobre e relevante função constitucional.

\section{Referências}

ASSOCIAÇÃO CEARENSE DO MINISTÉRIO PÚBLICO. Nota pública sobre Audiência de custódia . 2015. Disponível em: <http://acmp-ce.org.br/2015/07/nota-publica-sobre-audiencia-de-custo$\mathrm{dia} />$. Acesso em: 19 jun. 2017.

BOCATTO, Esdras. Direitos humanos e cumprimento das decisões internacionais no Brasil: instrumentos de execução interna das sentenças da corte interamericana de direitos humanos. Revista de Direito Constitucional e Internacional, São Paulo, a. 23. v. 91. p. 387-40, abr./jun. 2015.

BOBBIO, Norberto. A Era dos Direitos. Tradução Carlos Nelson Coutinho. Rio de Janeiro: Campus, 1992.

BRASIL. Constituição. República Federativa do Brasil de 1988. Brasília, DF: Senado Federal, 05 out. 1988. Disponível em: < http://www.planalto.gov.br/ccivil_03/constituicao/constituicaocompilado. htm >. Acesso em: 15 jun. 2017. 
BRASIL. Decreto n. 3.321, de 30 de dezembro de 1999. Promulga o Protocolo Adicional à Convenção Americana sobre Direitos Humanos em Matéria de Direitos Econômicos, Sociais e Culturais "Protocolo de São Salvador", concluído em 17 de novembro de 1988, em São Salvador, El Salvador. Diário Oficial da União, Brasília, DF, 31 dez. 1999. Disponível em: <http://www.planalto.gov.br/ ccivil_03/decreto/D3321.htm >. Acesso em: 13 jun. 2017.

BRASIL. Decreto n. 4.463, de 08 de novembro de 2002. Promulga a Declaração de Reconhecimento da Competência Obrigatória da Corte Interamericana de Direitos Humanos, sob reserva de reciprocidade, em consonância com o art. 62 da Convenção Americana sobre Direitos Humanos (Pacto de São José), de 22 de novembro de 1969. Diário Oficial da União, Brasília, DF, 11 nov. 2002. Disponível em: <http://www.planalto.gov.br/ccivil_03/decreto/2002/d4463.htm>. Acesso em: 03 jun. 2017.

BRASIL. Decreto n. 678, de 06 de novembro de 1992. Promulga a Convenção Americana sobre Direitos Humanos (Pacto de São José da Costa Rica), de 22 de novembro de 1969. Diário Oficial da União, Brasília, DF, 09 nov. 1992. Disponível em: <http://www.planalto.gov.br/ccivil_03/decreto/ D0678.htm>. Acesso em: 15 jun. 2017.

BRASIL. Lei Complementar n. 80/94, de 12 de janeiro de 1995. Organiza a Defensoria Pública da União, do Distrito Federal e dos Territórios e prescreve normas gerais para sua organização nos Estados, e dá outras providências. Diário Oficial da União, Brasília, DF, 13 jan. 1995. Disponível em: <http://www.planalto.gov.br/ccivil_03/leis/LCP/Lcp80.htm>. Acesso em: 14 jun. 2017.

CAPPELLETTI, Mauro; GARTH, Bryant. Acesso à Justiça. Tradução Ellen Gracie Northfleet. Porto Alegre: Sergio Antonio Fabris Editor, 1988.

CARVALHO, Salo de. Pena e garantias. Rio de Janeiro: Lumen Juris, 2008.

CHILE. Decreto Lei n².191, de 11 de abril de 1978. Condece amnistía a las personas que indica por los delitos de señala. Ministerio del Interior, Santiago de Chile, 19 abr. 1978. Disponível em: <http://www.usip.org/sites/default/files/file/resources/collections/commissions/Chile90-AmnestyLaw_decree2191.pdf>. Acesso em: 10 jun. 2017.

CONSELHO NACIONAL DE JUSTIÇA. Audiência de custodia. 2015. Disponível em: <http:// www.cnj.jus.br/sistema-carcerario-e-execucao-penal/audiencia-de-custodia >. Acesso em: 18 jun. 2017.

CONTESSE, Jorge. ¿̇La última palabra? Control de convencionalidad y possibilidades de diálogo con la Corte Interamericana de Derechos Humanos. In: IGLESIAS VILA, Marisa et al. Derechos humanos: possibilidades teóricas y desafios prácticos. Buenos Aires: Sela, 2013. Disponível em: <http://www.law.yale.edu/documents/pdf/sela/SELA13_Contesse_CV_Sp_20130401.pdf>. Acesso em: 12 jun. 2017.

CORTE INTERAMERICANA DE DIREITOS HUMANOS. Almonacid Arellano y Otros v. Chile. 2006. Disponível em: <http://www.corteidh.or.cr/docs/casos/articulos/seriec_154_esp.pdf>. Acesso em: 10 jun. 2017.

FALCONÍ, Ramiro J. García. Límites y alcances de la privación de libertad de acuerdo a la jurisprudência de la corte interamericana de derechos humanos. In: AMBOS, Kai. MALARINO, Ezequiel; ELSNER, Gisela (Ed.). Sistema interamericano de proteción de los derechos humanos y derecho penal internacional. Berlín: Konrad-Adenauer, 2011. Tomo II. p. 283-299. 
FERRAJOLI, Luigi. Direito e razão: teoria do garantismo penal. 2. ed. São Paulo: Revista dos Tribunais, 2006.

HITTERS, Juan Carlos. Un avance en el control de convencionalidad (el efecto erga omnes de las sentencias de La corte interamericana). Revista de Processo, São Paulo, a. 39. v. 234. p. 345-360, 2014

LASCALA, Maria Carolina Florentino. FREITAS, Riva Sobrado de. O Brasil e a cooperação jurídica internacional com a corte interamericana de direitos humanos. Revista Direitos Fundamentais e Justiça, Porto Alegre, a. 6, n. 18, p. 97-119, jan./mar. 2012.

LEITE, Antônio José Maffezoli. A atuação da defensoria pública na promoção e defesa dos direitos humanos, inclusive perante o sistema interamericano de direitos humanos. In: RÉ, Aluísio Iunes Monti Ruggere; REIS, Gustavo Augusto Soares dos. Temas aprofundados da defensoria pública. Salvador: Juspodivm, 2014. v. 2. p. 567-595.

MAZZUOLI, Valério de Oliveira. Curso de direitos humanos. Rio de Janeiro: Forense; São Paulo: Método, 2014.

NEVES, Marcelo. Do diálogo entre as cortes supremas e a Corte Interamericana de Direitos Humanos ao transconstitucionalismo na America Latina. Revista de Informação Legislativa, Brasília, DF, a. 51, n. 201, jan./mar. 2014.

ORGANIZAÇÃO DAS NAÇÕES UNIDAS. Carta da Organização das Nações Unidas, 1945. Disponível em: <https://nacoesunidas.org/carta/> . Acesso em: 10 jun. 2017.

ORGANIZAÇÃO DAS NAÇÕES UNIDAS. Declaração Universal dos Direitos Humanos, de 1948. Disponível em: <http://www.dudh.org.br/definicao/documentos/>. Acesso em: 21 jun. 2017.

ORGANIZAÇÃO DOS ESTADOS AMERICANOS. Convenção Americana de Direitos Humanos, de 1969. Disponível em: <https://www.cidh.oas.org/basicos/portugues/c.convencao_americana. htm >. Acesso em: 21 jun. 2017.

ORGANIZAÇÃO DOS ESTADOS AMERICANOS. Declaração Americana de Direitos e Deveres do Homem, de 1948. Disponível em: <https://www.cidh.oas.org/basicos/portugues/b.Declaracao_ Americana.htm>. Acesso em: 19 jun. 2017.

ORGANIZAÇÃO DOS ESTADOS AMERICANOS. Regulamento da Corte Interamericana de Direitos Humanos, de 16 a 28 de novembro de 2009. Disponível em: <http://www.corteidh.or.cr/sitios/reglamento/nov_2009_por.pdf>. Acesso em: 19 jun. 2017.

PELLEGRINI, Lisandro. El incumplimiento de las sentencias de la Corte Interamericana de Derechos Humanos. In: AMBOS, Kai; MALARINO, Ezequiel; ELSNER, Gisela (Ed.). Sistema interamericano de proteción de los derechos humanos y derecho penal internacional. Berlín: Konrad-Adenauer, 2011. Tomo I. p. 81-102.

PIOVESAN, Flávia. Direitos humanos e justiça internacional: um estudo comparativo dos sistemas regionais europeu, interamericano e africano. 4. ed. São Paulo: Saraiva, 2013.

PIOVESAN, Flávia. Direitos humanos e constitucionalismo regional transformador: o impacto do sistema interamericano. Revista dos Tribunais, São Paulo, a. 104, n. 952, p. 141-164, fev. 2015.

ROSA, Alexandre Morais da. O que é garantismo jurídico? Florianópolis: Habitus, 2003. 
SILVA, Cátia Aida Pereira. Justiça em jogo: novas facetas da atuação dos promotores de justiça. São Paulo: Edusp, 2001.

SILVA, Virgílio Afonso da. Colisões de direitos fundamentais entre ordem nacional e ordem transnacional. In: NEVES, Marcelo (Coord.). Transnacionalidade do direito: novas perspectivas dos conflitos entre ordens jurídicas. São Paulo: Quartier Latin, 2010.

STEINER, Sylvia Helena de Figueiredo. Convenção Americana sobre Direitos Humanos e sua integração ao processo penal brasileiro. São Paulo: Revista dos Tribunais, 2000.

STRECK, Lenio Luiz; SALDANHA, Jânia Maria Lopes. Ativismo e garantismo na Corte Interamericana de Direitos Humanos. In: DIDIER JÚNIOR, Fredie et al. (Coord.). Ativismo judicial e garantismo processual. Salvador: Juspodium, 2013. p. 413-414.

SUPREMO TRIBUNAL FEDERAL. RE 466.343 SP, de 2006. Relator: Min. Celso Peluso. Órgão Julgador: Tribunal Pleno. Julgamento em 03 ago. 2008. Diário de Justiça eletrônico, 04 jun. 2009. Disponível em: <http://www.stf.jus.br/portal/jurisprudencia/listarJurisprudencia.asp?s1=\%28466343. NUME. + OU + 466343.ACMS.\%29\&base=baseAcordaos\&url=http://tinyurl.com/lnca26w $>$. Acesso em: 10 jun. 2017.

Data da submissão: 27 de junho de 2016 Avaliado em: 30 de janeiro de 2018 (AVALIADOR A) Avaliado em: 29 de janeiro de 2018 (AVALIADOR B) Avaliado em: 16 de fevereiro de 2018 (AVALIADOR C) Aceito em: 13 de abril de 2018 